\title{
Treatment of Chronic Viral Hepatitis with Pegylated Interferon in Ivory Coast
}

\author{
Henriette Ya Kissi Anzouan-Kacou1, Aboubacar Demba Bangoura1, Djenabou Diallo1, \\ Yacouba Adéhouni2 , Adjeka Stanislas Doffou1, Hartrydt Dimitri Kouamé1, \\ Alassan Kouamé Mahassadi ${ }^{1}$, Mamert Fulgence Yao Bathaix ${ }^{1}$, \\ Alain Koffi Attia1, Aya Thérèse Ndri-Yoman'1 \\ ${ }^{1}$ Hepatogastroenterology Unit, Yopougon Teaching Hospital, Yopougon, Ivory Coast \\ ${ }^{2}$ Pharmacy Unit, Yopougon Teaching Hospital, Yopougon, Ivory Coast \\ Email: kissihy@yahoo.fr
}

Received 8 February 2016; accepted 11 March 2016; published 14 March 2016

Copyright (C) 2016 by authors and Scientific Research Publishing Inc.

This work is licensed under the Creative Commons Attribution International License (CC BY). http://creativecommons.org/licenses/by/4.0/

\section{Open Access}

\section{Abstract}

Background: In the Ivory Coast, chronic infection by hepatitis B and C virus is the leading cause of cirrhosis and hepatocellular carcinoma. The absence of universal health coverage makes the treatment inaccessible to all. Objectives: To assess the efficacy of Pegylated Interferon in clinical practice in patients with chronic viral hepatitis $B$ and $C$ and determine the hematologic side effects. Patients and Methods: A descriptive retrospective study from January 2012 to November 2013 on a cohort of patients chronic carriers of hepatitis $B$ virus $(n=11)$ treated with Pegylated Interferon to 180 mcg per week and hepatitis $C$ virus $(n=30)$ treated with a combination therapy associating pegylated Interferon to $180 \mathrm{mcg}$ per week and Ribavirin assayed according to the genotype. Results: Out of 1860 patients seen in hepatogastroenterology consultation 422 had viral hepatitis B or $C$ that is a prevalence of $22.7 \%$ and 41 patients were treated $(9.7 \%)$ by Pegylated Interferon. Among these 41 patients mentioned earlier, 30 had HCV (73.17\%) with a case of HIV + HVC co-infection, 11 patients had HBV (26.83\%) including 3 cases of HBV + HDV co-infection. Patients' age ranged from 24 - 69 years with an average of $49.2 \pm 12.2$ years including 46.5 years for HBV and 51.9 years for HCV. The sex ratio was 1.56. The original transaminases were on average 93.37 IU/l for AST and 110.47 for ALT. The average RNA HCV was $1,685,331 \mathrm{IU} / \mathrm{ml}$ and the DNA HBV $33,312,767 \mathrm{IU} / \mathrm{ml}$. Patients with HCV were of genotype 1 in $56.66 \%$, genotype 2 in $40 \%$ and one case of genotype 4 (3.34\%) from Central Africa. Fibrosis score at institution of treatment was significant $\left(\geq A 2\right.$ and/or $\geq F 2$ ) in $86.9 \%$ of cases of Fibrotest ${ }^{\circledR}, 100 \%$ of cases of Fibrometer $®$. We observed $48.8 \%$ of neutropenia $<750 / \mathrm{mm}^{3}, 33.3 \%$ of anemia and $29.3 \%$ of thrombocytopenia < $100,000 / \mathrm{mm}^{3}$. There was no dose reduction of Pegylated Interferon and Ribavirin. For HBV there were 3 partial responses, 3 responders including $1 \mathrm{HBV}+\mathrm{HDV}$ co-infected non responder to HDV, 2 non responders including $1 \mathrm{HBV}+\mathrm{HDV}$ co-infected to Week 48. For HCV, there was $52.94 \%$ of cases of sustained viral response (SVR) including 44.44\% of genotype 1, 83.33\% of genotype 2 and 
$100 \%$ of genotype 4 . Conclusion: The free antiviral treatment program helped treat $10 \%$ of chronic viral hepatitis B and C. Our results are not different from those of the literature. Difficulties remain in the performance of non supported diagnostic tests.

\author{
Keywords \\ HBV, HCV, Pegylated Interferon, Ribavirine, Africa
}

\title{
1. Introduction
}

The vast majority of individuals infected with viral hepatitis are in low and middle-income countries of Africa and Asia, where the screening and access to treatment are not available [1]. The main objective of treatment of chronic hepatitis B and C is to obtain a durable suppression of viral replication in order to improve histological lesions and therefore reduce the risk of progression to cirrhosis, and hepatocellular failure and hepatocellular carcinoma [2]. Following "the Dakar Appeal” [3], the Ivorian government, through the National Program of the Fight against Viral Hepatitis (NPFVH) has made freely available to patients of the 3 Teaching Hospitals of Abidjan, Pegylated Interferon (PEG-IFN) from February 2012 to November 2013 for the treatment of chronic hepatitis B and C. The pre, per and post therapeutic biological, radiological and histological tests remain the responsibility of patients. If the fight against viral hepatitis begins in Africa, the management of affected people remains little studied [4]. Among the studies carried out in this country on viral hepatitis, very few have focused on treatment. We carried out a study on the results of treatment with PEG-IFN, in patients with chronic hepatitis during this period at the Teaching Hospital of Yopougon in Abidjan in the Ivory Coast.

The aims of our work were to assess the effectiveness of treatment with PEG-INF alone or in combination with Ribavirin (RBV) in clinical practice in patients with chronic hepatitis B or C and to determine the hematologic side effects.

\section{Patients and Methods}

The Teaching Hospital of Yopougon is the third university hospital situated in the biggest municipality of Abidjan with a capacity of 508 beds. The consultation in hepatogastroenterology is assured by 6 specialists who receive 3600 patients a year.

We carried out a single-center retrospective study of patients with chronic hepatitis B or C, followed in the hepatogastroenterology consultation department of the Teaching Hospital of Yopougon and candidates according to the international recommendations for antiviral treatment. The medical records of these patients were collected over a period from February 1, 2012 to November 30, 2013 as cases. The inclusion criteria were: chronic active HBV or HCV (HBs Ag positive for more than 6 months, positive anti HCV antibody, persistent or intermittent elevated transaminases, HVB DNA $\geq 2000 \mathrm{IU} / \mathrm{ml}$ for Hbe Ag negative or $\geq 20000 \mathrm{IU} / \mathrm{ml}$ for $\mathrm{Hbe} \mathrm{Ag}$ positive, positive HVC RNA, a necroinflammation or 1 moderate to severe fibrosis), absence of HBV + HIV co-infection, treatment with PEG-IFN. Were excluded: patients with HBV + HIV co-infection, chronic inactive hepatitis B, the untreated HBV or HCV or treated by another molecule. The following parameters were investigated: demographic (age, gender), biochemical (transaminases), serum (HBs antigen, total HBc-Ab, Hbe Ag, Hbe-Ab, HCV-Ab), virological (HBV DNA and HCV RNA quantitative by PCR). Hbe Ag, Hbe-Ab, HCV-Ab were detected by ELISA test (Biomerieux Clinical Diagnostics, Geneva, Switzerland). HBV DNA was measured by the technique COBAS Ampliprep/COBAS TaqMan HBV Version 2.0 from Roche (Meylan, France) with a $20 \mathrm{IU} / \mathrm{ml}$ positivity threshold (linearity of $20 \mathrm{IU} / \mathrm{ml}$ to 170,000,000 IU/ml). The quantification of RNA-HCV was performed by PCR in real time according to the Roche technique (CobasTaqMan ${ }^{\circledR}$ ), sensitivity $15 \mathrm{IU} / \mathrm{ml}$ (1.2 log), linearity: 44 - 69,000,000 IU/ml (1.6 to $7.8 \mathrm{log}$ ). Liver fibrosis was assessed by non-invasive methods (Fibrotest ${ }^{\circledR}$-Actitest ${ }^{\circledR}$ Biopredictive or Fibrometer ${ }^{\circledR}$ V Biolivescale or FibroScan ${ }^{\circledR}$ VTME) or by a liver biopsy. When the biopsy was available, the data were compiled according to the METAVIR scoring system: A0 for no activity A1 for minimal activity A2 for moderate and A3 for severe; F0 as no fibrosis, F1 for portal fibrosis without septa, F2 for fibrosis with rare septa, F3 for fibrosis with many septa and F4 for cirrhosis. All patients had had an abdominal ultrasound in search of cirrhosis or hepatocellular carcinoma (HCC) signs. 
A comprehensive pre-therapeutic assessment in search of absolute or relative contra-indications was performed in all patients. The patients were put on PEG-IFN $\alpha 2$ a alone at a dose of 180 mcg per week for 48 weeks in the case of HBV and indefinitely in the case of HBV + HDV co-infection. In the cases of HCV, PEG-IFN $\alpha 2 \mathrm{a}$ was combined with RBV and administered at doses varying according to weight. For genotypes 1 and 4:1, 000 $\mathrm{mg} /$ day below $75 \mathrm{~kg}$ and $1200 \mathrm{mg} /$ day beyond. Doses were fixed at $800 \mathrm{mg} /$ day for genotype 2 . The duration of treatment was 48 weeks for patients with HCV of genotype 1 or 4 of 24 weeks in patients with HCV of genotype 2. All patients included had a follow-up superior or equal to 6 months after treatment.

For HBV, the viral load was assayed by PCR for the initiation of treatment, to week 12, week 24, week 48 and 6 months after the end of treatment. The subject was considered responder if the viral load was negative at the end of treatment. The response was considered partial if there was a decrease without viral negativation. The non-response was defined by the persistence of the HBV DNA in the serum at the end of treatment. The viral response was sustained if six months after completion of treatment the viral load remained negative; the patient was a responder relapser if the viral load became detectable 6 months after the end of treatment. For HCV the viral load was assayed by PCR at initiation of treatment, to week 4 if genotype 1, week 12, week 24 and week 48 and 6 months after the end of treatment. Virological response to treatment was considered fast if the viral load was undetectable at week 4 , early if the viral load decreased by 2 logs to week 12 . The subject was considered responder if the viral load was negative at the end of treatment. The response was considered partial if there was a decrease without viral load negativation. The non response was defined by the persistence of the viral RNA C in the serum at the end of treatment. Viral response was sustained if six months after the end of treatment the viral load remained negative; the patient was a responder relapser if the viral load became detectable 6 months after the end of treatment. The main objective of treatment was a sustained viral response, defined by HCV RNA of or HBV DNA undetectable six months after the end of treatment.

\subsection{Statistical Analyses}

Data were processed and analyzed using Microsoft Excel 2010 software (Microsoft, Seattle, WA, USA). The description of the sample consisted of calculations of proportions for qualitative variables and averages with their standard deviation for quantitative variables.

\subsection{Ethical Consideration}

Since it was for author's personal use counting records, patient consent was not required. However during the counting and data collection patients names were not collected in order to preserve confidentiality.

\subsection{Results}

During the study period, 1860 patients were seen in consultation of hepatogastroenterology and the number of patients with chronic viral hepatitis C or B was 422 that is a prevalence of $22.7 \%$. 44 patients were put on pegylated Interferon that is $10.43 \%$ of which 41 records were exploitable.

\section{Characteristics of the Study Population}

Among these 41 patients, 30 had HCV (73.17\%) with a case of HIV + HVC co-infection, 11 patients had HBV (26.83\%) including 3 cases of HBV + HDV co-infection. Patients' age ranged from 24 to 69 years with an average of $49.2 \pm 12.2$ years including 46.5 years for HBV and 51.9 years for HCV. The sex ratio was 1,56 . The level of education was higher education in 52.5\%, level of secondary school in 30\%, and level of primary-school in $5 \%$ and no education in $12.5 \% .82 .92 \%$ of patients had a paid employment. Co-morbidities were: 11 hypertension, 7 diabetes, $1 \mathrm{HIV}, 1$ thyroid nodule.

2 patients with HCV had already been treated by combination therapy, including 1 of genotype 1 non-responder to the combination therapy pegylated Interferon and Ribavirin and the second of genotype 2 whose treatment was stopped at 3 months for severe neutropenia.

Physical examination did not reveal any sign of portal hypertension or hepatocellular failure or morphological change of liver.

Biochemically, the original transaminases were on average 93.37UI/l (15 - 526) for AST and 110.47 (11 - 706) 
for ALT. In our HBV patients, the assessment at baseline showed mean transaminase values that were AST = $111.9 \mathrm{IU} / \mathrm{ml}$ and ALT = $184.2 \mathrm{IU} / \mathrm{ml}$.

Virologically, the average viral load was $1.685 .331 \mathrm{IU} / \mathrm{ml}(13,915$ - 13,600,000) for HCV and 33,312,767 IU/ml for HBV (547 - 124,871,948).

HCV patients were of genotype 1 in 17 cases (56.66\%), genotype 2 in 12 cases (40\%) and 1 case of genotype 4 (3.34\%) from Central Africa.

The fibrosis score at initiation of treatment was significant $\left(\geq A 2\right.$ and $/$ or $\geq F 2$ ) in $86.9 \%$ of cases of Fibrotest ${ }^{\circledR}$ $(n=24), 100 \%$ of cases of Fibrometer ${ }^{\circledR}(n=14)$.

The activity was classified A0 $(n=3)$, A1 $(n=5)$, A2 $(n=5)$ A3 $(n=11)$ and fibrosis was classified F0 $(n=$ 1), F1 $(n=2)$ F2 $(n=6), F 3(n=4)$ and F4 $(n=11)$ in the 24 Fibrotests ${ }^{\circledR}$. The activity was classified A0 $(n=0)$, A1 $(n=3)$, A2 $(n=6)$ A3 ( $=5)$ and fibrosis was classified F0 $(n=0)$, F1 $(n=0)$ F2 (n= 6), F3 (n= 5) and F4 $(\mathrm{n}=3)$ in the 14 Fibrometers ${ }^{\circledR}$. $36.84 \%$ of patients were classified $\mathrm{F} 4$ : it was therefore about decompensated cirrhosis.

Abdominal ultrasound was normal in 39 patients (95\%) and 2 cases showed homogeneous hepatomegaly (5\%). There were no signs of cirrhosis or portal hypertension or hepatocellular carcinoma.

2 fibroscans were performed including 1 case that was F1 and 1 case was F2.

The fibrosis score at initiation of treatment was significant ( $\geq \mathrm{A} 2$ and/or $\geq F 2$ ) in $71.4 \%$ of cases of liver biopsy $(n=7)$ the activity was classified A0 $(n=1)$, A1 $(n=2), A 2(n=3)$ A3 $(n=1)$ and fibrosis was classified F0 (n $=0)$, F1 $(n=2)$, F2 $(n=2)$, F3 $(n=3)$ and F4 $(n=0)$.

Table 1 presents the characteristics of the patients to the inclusion.

\section{Duration of Treatment}

Seven patients discontinued their treatment that is $17.07 \%$ of cases. It was 4 cases of HCV of genotype 1 (23.5\%), whose discontinuation of treatment occurred 40 and 38 weeks for no decline in viral load to 16 weeks, for cirrhosis decompensation and to 4 weeks for pyoderma. 3 cases of HBV had to discontinue their treatment (27.3\%) to 20 weeks because PEG-IFN $\alpha 2$ a was out of stock, to 32 weeks for poor adherence and to 36 weeks for severe thrombocytopenia. PEG-IFN $\alpha 2 \mathrm{a}$ was replaced by tenofovir in these three cases.

$13 \mathrm{HCV}$ of genotype 1 (76.5\%) underwent 48 weeks of combination therapy, $12 \mathrm{HCV}$ of genotype 2 (100\%) underwent 24 weeks of combination therapy and genotype 4 (100\%) underwent 48 weeks of combination therapy. $8 \mathrm{HBV}$ (72.7\%) underwent 48 weeks of PEG-IFN $\alpha 2$ a monotherapy.

Table 1. Characteristics of the patients in the inclusion $(n=41)$.

\begin{tabular}{|c|c|c|c|}
\hline Paramètres & All n (\%) & HVB n (\%) & HVC n (\%) \\
\hline Frequency & 422 (22.7) & $11(26.8)$ & 30 (73.18) \\
\hline Average age (extremes) & $49.2 \pm 12(24-69)$ & $42.3(24-69)$ & $51.9(27-68)$ \\
\hline Gender male & 25 (69.98) & $10(90.9)$ & $15(50)$ \\
\hline $\mathrm{ALT} \geq 2 \mathrm{~N}(\mathrm{IU} / \mathrm{l})$ & $17(41.46)$ & $6(54.55)$ & $11(46.67)$ \\
\hline $\mathrm{AST} \geq 2 \mathrm{~N}(\mathrm{IU} / \mathrm{l})$ & $16(39.1)$ & $3(27.2)$ & $13(43.33)$ \\
\hline HBe negative antigen & & $9(81.82)$ & \\
\hline HCV genotype 1 & & & 17 (56.66) \\
\hline 2 & & & $12(40)$ \\
\hline 4 & & & $1(3.34)$ \\
\hline $\mathrm{HCV} \mathrm{RNA} \geq 800000 \mathrm{UI} / \mathrm{ml}$ & & & $14(46.67)$ \\
\hline $\mathrm{HBV} \mathrm{DNA} \geq 800000 \mathrm{UI} / \mathrm{ml}$ & & $4(36.36)$ & \\
\hline$\geq \mathrm{A} 2$ & $27(71)$ & & \\
\hline$\geq \mathrm{F} 2$ & 35 (92.1) & & \\
\hline
\end{tabular}




\section{Hematological Adverse Reactions}

20 cases (48.8\%) of neutropenia $<750 / \mathrm{mm}^{3}$ were observed, with the lowest rate to $221 / \mathrm{mm}^{3}$ including 16 (80\%) that received filgrastim (Neupogen $\left.{ }^{\circledR} 34\right)$ ). 12 cases (29.3\%) of thrombocytopenia $<100,000 / \mathrm{mm}^{3}$ whose lowest rate was to 11,000 platelets $/ \mathrm{mm}^{3}$ due to PEG-IFN $\alpha 2$ a.

We noted 10 cases of anemia $<10 \mathrm{~g} / \mathrm{dl}(33.3 \%)$ due to RBV with the lowest rate of $8.6 \mathrm{~g} / \mathrm{dl}$, who all received erythropoietin (100\%).

There was no dose reduction of PEG-IFN or RBV.

Only one patient had to discontinue treatment because of severe thrombocytopenia to 11,000 platelets $/ \mathrm{mm}^{3}$ : it was 1 case of HBV which continued treatment with tenofovir.

\section{Virological Response}

\subsection{HBV}

3 partial responses, 3 responders including $1 \mathrm{HBV}+\mathrm{HDV}$ co-infected non responders to HDV,

2 non responders including $1 \mathrm{HBV}+\mathrm{HDV}$ co-infected to week 48. Which makes after 6 months of treatment: $12.5 \%$ SVR, $75 \%$ non-responders and $12.5 \%$ responders relapsers.

\subsection{HCV}

One genotype 1 patient had had 1 RVR with viral load negativation to week 4.

3/17 patients with genotype 1 had had 1 early virological response (EVR) with a decrease of 2 logs to Week 4.

12/30 patients had viral load negated to Week 12 with 5/17 of genotype 1, 6/12 of genotype 2 and 1/1of genotype 4.17 negated to Week 24 with 6/17 of genotype 1, 11/12 of genotype 2 and 1/1 of genotype 4 .

The virological response at the end of the treatment was: 9/17 cases of genotype 1 had negated to Week 48, $11 / 12$ cases of genotype 2 and $1 / 1$ case of genotype 4 . There were $52.94 \%$ of cases of SVR including $44.44 \%$ of genotype $1,83.33 \%$ of genotype 2 and $1 / 1$ case of genotype 4 .

Table 2 presents the patients results.

\section{Discussion}

This retrospective study presents limits. The various modes of contamination were not able to be specified. The data we report can not reflect the situation in the general population. In spite of these limits, this study allowed to appreciate the effectiveness of treatment with PEG-INF alone or in combination with Ribavirin (RBV) inclinical practice.

In our study, out of 1860 patients seen in hepatogastroenterology consultation, 422 that is $24.7 \%$ had chronic hepatitis B or C. Only 44 patients that is $10.4 \%$ had had access to treatment with PEG-IFN free. In Gabon 4.5\% of HBV and 9.8\% of HCV were put on treatment [5], while in Burkina Faso [6] 39\% of HCV patients were treated in a public hospital. A study in Cameroon in a private medical center treated $73.17 \%$ of HCV patients [7].

Table 2. Treatment results.

\begin{tabular}{cccc}
\hline Parameters & All n(\%) & HBV n (\%) & HCV n (\%) \\
\hline Naïve & $38(92.6)$ & $10(90.9)$ & $28(93.3)$ \\
Discontinuation & $7(17)$ & $3(27.3)$ & $4(13.3)$ \\
Neutropenia & $20(48.8)$ & $5(45.4)$ & $15(50)$ \\
Anaemia & $10(24.4)$ & $0(0)$ & $10(33.3)$ \\
Thrombocytopenia & $12(29.2)$ & $5(45.4)$ & $18(60)$ \\
SVR & $19(46.3)$ & $6(54.5)$ & $5(16.6)$ \\
Non responder & $11(26.8)$ & $1(9)$ & $3(10)$ \\
Responder relapser & $4(9.7)$ & & \\
\hline
\end{tabular}


Patients of Teaching Hospitals came from socially disadvantaged social classes, as for wealthy people they seek treatment in private structures [4]. In a study carried out in 2013 on Ivorian patients' representations and experiences of HBV in Abidjan, out of 14 patients only 2 had had access to treatment. All patients met or had encountered difficulties to bear the financial burden of pre-therapeutic assessment or monitoring due to the cost of transportation, laboratory exams, and consultations [4]. The low rate of patients put on treatment in public hospitals despite the high endemicity of viral hepatitis in our countries of Sub Saharan Africa, is explained by the absence of social security coverage. The problems raised by the treatment of viral hepatitis by PEG-IFN are essentially economic. The second problem is the mode of administration of Interferon that is injectable and requires storage at $4^{\circ} \mathrm{C}$. We are also faced with the problem of virological monitoring of treated patients [8].

The average age of our patients was 49.2 years. They were 42.3 years old for VHB which is consistent with other studies carried out in Côte d'Ivoire that found an average age of 42 years for chronic carriers of HBs Ag [9] and 40 [10], in France HBV patients had a median age of 44 years [11]. Our HCV patients were on average 51.9 years old, in line with SOMBIE et al. who found an average age of $51 \pm 6.9$ years in HCV patients put on treatment [6] and a study in Morocco where HCV patients were on average 52 years old [12], in Tunisia the average age of HCV patients was 50 years [13] and $53.1 \pm 8.1$ years in Cameroon [7]. HCV Japanese patients had an average age of 55 years [14].

Our sex ratio was 1.56. Which is higher than HCV patients in Burkina Faso 1.25 [6] and in Tunisia whose patients had a sex ratio of 1.04 [13] but is consistent with Japanese patients who had a sex ratio of 1.57 [14].

We had no case of HBV + HCV co-infection. Bignomba found 4.2\% of HBV + HCV co-infection [5]. We identified 3 cases of HBV + HDV co-infection (27.3\%) and 1 case of HCV +HIV co-infection (3.3\%). Because of the common modes of transmission, the co-infection of viral hepatitis with HIV is common. Out of the 34 million people infected with HIV worldwide, $5 \%$ - 25\% are also co-infected with HBV (2 - 4 million, 5\% - 20\%) and/or HCV (4 - 5 million, 5\% - 15\%). Developing countries face the double burden of co-infection [15]. The co-infection or superinfection HIV-HBV or HCV is then common in these areas, the transmission modes being crossed [16]. In the Ivory Coast, the HBV + HIV co-infected patients are put on anti retroviral drugs including Lamivudine and Tenofovir which explains the absence of HBV + HIV co-infected patients in our study.

None of our patients on treatment had clinical or radiological evidence of cirrhosis or hepatocellular carcinoma. But the fibrosis score was F4 in $36.84 \%$ of cases, this was compensated cirrhosis. Viral hepatitis is often diagnosed at the stage of cirrhosis in our country.

\section{Duration of Treatment}

The disadvantages of interferon are subcutaneous administration and the frequency of side effects, although the tolerance of the treatment looks better in hepatitis B than in hepatitis C [17]-[21]. Regarding the duration of treatment of our patients, 7/41 (17\%) discontinued their therapy: they were 4 HCV all of genotype 1 for nonresponse, 1 decompensated cirrhosis and 1 infection of type pyoderma and $3 \mathrm{HBV}$ including 1 for severe thrombocytopenia. Our rates are higher than those found in Tunisia, 10/141 (7.1\%) patients had to discontinue treatment permanently, in all cases because of adverse effects of treatment which were mainly of hematological order $(n=7)$. The other causes of discontinuation were autoimmune hepatitis $(n=1)$ and acute renal failure $(n=$ 2) [13]. In a meta-analysis, despite reports that the treatment of HCV is associated with significant side effects, only $4 \%$ of enrolled patients discontinued treatment because of side effects [22]. In one study on the tolerance of the combination pegylated Interferon-Ribavirin therapy in HIV-HCV co-infected patients, the intolerance to treatment justified a dosage reduction of at least one anti-HCV drugs in $40 \%$ and the premature discontinuation of treatment in $12 \%$ [23]. In the Japanese study the cumulative discontinuation due to side effects of therapy was $14.9 \%$ to one year, statistically significant in patients $>65$ years and in patients who had diabetes [14].

\section{Hematological Side Effects}

These therapies are associated with several hematopoietic side effects such as anemia, thrombocytopenia and neutropenia, causing discontinuations of treatment or dose reductions that may lead to a suboptimal therapeutic efficacy [19]-[21].

In our study, 20/41 cases (48.8\%) of neutropenia $<750 / \mathrm{mm}^{3}$ were observed, with the lowest rate to $221 / \mathrm{mm}^{3}$ including 16 (80\%) who received Filgrastim. 12 cases (29.3\%) of thrombocytopenia $<100,000 / \mathrm{mm}^{3}$ whose lowest rate was to 11,000 platelets $/ \mathrm{mm}^{3}$ due to pegylated Interferon $\alpha 2 \mathrm{a}$. We noted 10 cases of anemia $<10 \mathrm{~g} / \mathrm{dl}$ 
(33.3\%) due to Ribavirin with the lowest rate to $8.6 \mathrm{~g} / \mathrm{dl}$, which all received erythropoietin (100\%). There was no dose reduction of pegylated Interferon or Ribavirin. One single patient had to discontinue treatment because of severe thrombocytopenia to 11,000 platelets $/ \mathrm{mm}^{3}$ : it was 1 case of HBV which continued treatment with Tenofovir.

In Tunisia, adverse effects were noted in 67 patients $(47 \%)$, hematologic disorders in majority $(n=54)$. Erythropoietin was used in 17/34 (50\%) of patients with anemia and Lenograstim in 13/19 (68\%) of patients with neutropenia. A dosage reduction in treatment was reported in 23 patients (16.3\%), in all cases due to adverse hematological effects [13]. Sombié et al. noted 1 anemia in 2/18, leukopenia in 6/18 and thrombocytopenia in 2/18 [6]. In Cameroon out of 90 patients who were treated for at least 12 weeks, 6 (6.7\%) discontinued treatment because of adverse events (neutropenia, encephalitis, pancytopenia and thrombocytopenia) [7]. The probability of SVR depends on the good adhesion to the therapy (at least $80 \%$ of the required dose was maintained for at least $80 \%$ of the time required) and appropriate adhesion can only be achieved if the side effects are reduced to a minimum [23]. The hematopoietic growth factors, erythropoietin or granulocyte colony stimulating factor (GCSF) are effective to limit dose reductions of Ribavirin related to anemia or of IFN related to neutropenia [19] [20]. The consequences of these premature discontinuations can cause a decrease in EVR and therefore a risk of progression of liver disease [24]. Despite the lack of marketing authorization in the treatment of hepatitis C, erythropoietin helps improve the quality of life of patients made anemic and maintain adequate doses of Ribavirin. The use of G-CSF is even more controversial because the link between neutropenia (induced here by Interferon) and viral infection is not as obvious as in cancerology. Thrombocytopenia was mainly due to the effect of myelosuppression of the IFN and requires a dose reduction only in $3 \%-6 \%$ of randomized assays using PEGIFN [24]. Although studies have demonstrated that the use of hematopoietic growth factors really reduces the incidence and severity of these side effects and helps patients to complete therapy, data on the improvement of SVR remain limited [25].

\section{VHB Virological Response}

Among Hbe Ag positive and negative patients, the therapeutic end point is sustained HBs Ag loss with or without HBs seroconversion. Among Hbe Ag positive patients, durable HBe seroconversion is a satisfactory end point because it is shown to be associated with an improved prognosis [26]. PEG-IFN alfa-2a, for 48 weeks resulted in a $27 \%$ rate of Hbe Ag seroconversion and 25\% of HBV DNA negativation. Six months after discontinuing treatment, Hbe Ag seroconversion rates reach 32\%. The loss of Hbs Ag with the appearance of Anti-HBs occurred in $4 \%-6 \%$ of patients after 1 year of treatment and 6 months of post-treatment follow-up [26].

We noted 1 (12.5\%) SVR, 6 (75\%) non-responders including 3 partial responses and 1 (12.5\%) responder relapser. Moucari et al. in France found 48 patients, 30 (62\%) had had a response at the end of treatment and 18 (38\%) were non-responders. Twenty-four weeks after discontinuing treatment, only 12 (25\%) patients had a SVR, while 18 (38\%) patients relapsed. They concluded that the quantification of the HBs Ag appears to be an excellent marker to predict sustained response to treatment and identify in the first phase of PEG-IFN patients who will most likely respond to this treatment [11]. A rapid decline of Hbs Ag rate is predictive of a SVR. The rates of HBs Ag to week 12 and 24 after the start of treatment were associated with the identification of non responders or to adapt the duration of treatment in responders. The lack of significant decline in the HBs Ag to week 12 of PEG-IFN is a strong negative predictor of response of Hbe Ag positive patients. HBs Ag is an important test that marks not only the active infection with HBV, but also can predict the clinical outcome of infection. Based on the quantification of HBs Ag a response guided therapy in HBs Ag positive patients as well as in Hbe Ag negative treated with PEG-IFN was developed [27]. The effectiveness of drugs available for the treatment of chronic hepatitis B was assessed in randomized controlled trials over a year. HBe seroconversion rate was about 30\% with conventional and pegylated Interferon alpha and approximately 20\% with nucleotide analogs. The loss of HBs Ag was 3\% - 4\% after a one-year treatment with pegylated Interferon alpha, $0 \%$ after treatment with lamivudine, adefovir and telbivudine, $2 \%$ after treatment with entecavir, and $3 \%$ after treatment with tenofovir. In Hbe Ag negative patients, the virological response rate to one year (variously defined in different trials and differently to recommendations) were $63 \%, 72 \%, 51 \%, 90 \%, 88 \%$ and $91 \%$ with treatment with pegylated Interferon alpha2a, lamivudine, adefovir, entecavir, telbivudine and tenofovir. The loss of $\mathrm{HBs} \mathrm{Ag}$ was 3\% after a one-year treatment with pegylated Interferon alpha and $0 \%$ after treatment with lamivudine, adefovir, entecavir, telbivudine or tenofovir [26]. The benefits of treatment with PEG-IFN are in addition to the limited treatment duration of 48 weeks, the possibility of a SVR after discontinuing treatment with HBe seroconversion in one third of patients in the short term and HBV DNA undetectable in 17\% of HBe negative patients. 
In the long term, HBs seroconversion was observed in almost $10 \%$ of patients. Finally PEG-IFN does not cause resistance [26].

\section{HCV Virological Response}

The combination therapy PEG-INF + Ribavirin remains the standard treatment for the majority of HCV patients worldwide. However, the new antiviral drugs with direct action can become the standard of care in most rich countries. However, the high costs and pharmaceutical patents of these new drugs, that also require regular specific monitoring, make these treatments unavailable in low and middle-income countries [15]. In our study, 1 (5.8\%) genotype 1 patient had had 1 RVR with viral load negativation to week 4.3 (17.6\%) patients with genotype 1 had had 1 EVR with 2 logs decrease to week 4.12 (40\%) patients had their viral load negated to week 12 including 5 (29.4\%) of genotype 1, 6 (50\%) of genotype 2 and 1 of genotype 4.17 negated to week 24 including 6 (35.2 \%) of genotype 1,11 (91.6\%) of genotype 2 and 1 of genotype 4.9 (52.9\%) patients of genotype 1 negated to week 48. Therefore There had been across all genotypes, $52.94 \%$ of cases of SVR including $44.44 \%$ of patients with genotype $1,83.33 \%$ of patients with genotype 2 and $1(100 \%)$ patient with genotype 4 . Out of the 90 Cameroonian patients, 61 (67.8\%) had had 1 EVR: 22/34 (64.7\%) of HCV genotype 1 patients, 19/21 (90.5\%) of HCV genotype 2 and 20/35 (57.1\%) of HCV genotype 4. There was no significant difference between the virological response of HCV genotype 1 and that of HCV genotype 4 patients $(\mathrm{P}=0.52)$, while HCV genotype 2 patients had a rate of SVR higher than that of HCV genotype 1 and HCV genotype 4 patients $(P=0.05)$ [7]. A meta-analysis that included 93 studies of low and intermediate-income countries showed that HCV treatment success rate in these patients is similar to the rate reported in patients of rich countries [22].

In Tunisia, the rate of virological response at the end of treatment in intention to be treated across all genotypes, was $83 \%(n=117)$. The SVR rate was $66 \%(n=93)$. Among patients infected with HCV of genotype 1 , the SVR rate in intention to be treated was $58.5 \%(n=62)$. This rate was $91 \%(n=31)$ in case of HCV of genotype 2 or 3 [13]. Hepburn also demonstrated that the SVR differs according to ethnic groups: it was higher in Asians 22/36 (61\%), followed by caucasiens 193/496 (39\%), Hispanics 18/79 (23\%) and African Americans $7 / 50$ (14\%) [28]. In an American study comparing the SVR of African Americans to that of Caucasians with the pegylated combination therapy, it was reached respectively in $28 \%$ and $52.8 \%(\mathrm{p}<0.0001)$. This study suggests that the low rate of response of African-Americans compared to Caucasians' is not due to clinical characteristics of patients, severity of illness, or the amount of drugs taken. The race remains significantly and independently associated with SVR [29].

\section{Conclusion}

The free antiviral treatment program helped treat $10 \%$ of chronic viral hepatitis B and C. Our results are not different from those of the literature. Difficulties remain in the performance of non-supported diagnostic tests. PEG-INF is State-subsidized in the 3 Teaching Hospitals of Abidjan since 2015 making it accessible to our patients, which will allow handling a largest number of chronic viral hepatitis.

\section{References}

[1] Lemoine, M., Eholié, S. and Lacombe, K. (2015) Reducing the Neglected Burden of Viral Hepatitis in Africa: Strategies for a Global Approach. Journal of Hepatology, 62, 469-476. http://dx.doi.org/10.1016/j.jhep.2014.10.008

[2] Shepard, C.W., Finelli, L. and Alter, M.J. (2005) Global Epidemiology of Hepatitis C Virus Infection. The Lancet Infectious Diseases, 5, 558-567. http://dx.doi.org/10.1016/S1473-3099(05)70216-4

[3] Conférence internationale des acteurs de lutte contre les hépatites en Afrique francophone. (2011) Appel de Dakar.

[4] Pourette, D. and Enel, C. (2014) Représentations et vécu de l'hépatite B de patients subsahariens en Côte d'ivoire et en France. Santé Publique, 26, 869-878.

[5] Bignoumba Ibouili, R., Iba Ba, J., Itoudi Bignoumba, P.E., Missounga, L., Eyi Nguema, A.G., Pemba, L., Coniquet, S., Moussavou Kombila, J.B. and Boguikouma, J.B. (2012) Aspects socioéconomiques de la prise en charge des hépatites chroniques B et C à Libreville (Gabon). Médecine et Santé Tropicales, 22, 101-102 .

[6] Sombié, R., Bougouma, A., Somda, S., Sangare, L., Lompo, O., Kabore, Z., Tieno, H., Drabo, J. and Ilboudo, D. (2011) Hépatite C chronique: Epidémiologie, diagnostic et traitement au CHU Yalgado-Ouédraogo de Ouagadougou. Journal Africain d'Hépato-Gastroentérologie, 5, 6-13. http://dx.doi.org/10.1007/s12157-010-0213-7 
[7] Njouom, R., Tagni Sartre, M., Timba, I., Nerrienet, E., Tchendjou, P., Pasquier, C. and Rousset, D. (2008) Efficacy and Safety of Peginterferon Alpha-2a/Ribavirin in Treatment-Naïve Cameroonian Patients with Chronic Hepatitis C. Journal of Medical Virology, 80, 2079-2085. http://dx.doi.org/10.1002/jmv.21319

[8] Organisation mondiale de la Santé (2013) Hépatite virale: Analyse de situation et perspectives dans la région africaine. Plan d'action mondial pour les vaccins 2011-2020. Genève.

[9] Attia, K.A., Kissi,Y.H., Doffou, S., Bangoura, D., Wilson, R.F., Bougha, G., Yao Bathaix, F., Mahassadi, K.A., Sayegh, M. and N'dri-Yoman, T. (2013) Prevalence of Hepatitis B Infection and Factors Associated in Children of Ivorian HBs Ag Carrier Subjects. Open Journal of Gastroenterology, 3, 237-240. http://dx.doi.org/10.4236/ojgas.2013.34040

[10] Attia, K.A., Doffou, S., Kissi, Y.H., Bangoura, D., Seka, M.P., Mahassadi, K.A., Yao Bathaix, F., Sayegh, M. and N'dri-Yoman, T. (2013) Virological Profile of Hepatitis B infection in Black African HBs Ag Chronic Carriers. Open Journal of Gastroenterology, 3, 113-118. http://dx.doi.org/10.4236/ojgas.2013.32019

[11] Moucari, R., Mackiewicz, V., Lada, O., Ripault, M-P., Castelnau, C., Martinot-Peignoux, M., Dauvergne, A., Asselah, T., Boyer, N., Bedossa, P., Valla, D., Vidaud, M., Nicolas-Chanoine, M.-H. and Marcellin, P. (2009) Early Serum HBs Ag Drop: A Strong Predictor of Sustained Virological Response to Pegylated Interferon Alfa-2a in Hbe Ag-Negative Patients. Hepatology, 49, 1151-1157. http://dx.doi.org/10.1002/hep.22744

[12] Cacoub, P., Ohayon, V., Sekkat, S., Dumont, B., Sbai, A., Lunel, F., Benslimane, A., Godeau, P. and Archane, M.I. (2000) Etude épidémiologique et virologique des infections par le virus de l'hépatite C au Maroc. Gastroentérologie Clinique et Biologique, 24, 169-173.

[13] Sondes, B., Hatem, B.A., Ichrak, K., Ghanem, M., Riadh, B. and Nabil, A. (2013) Facteurs prédictifs de réponse à la bithérapie pégylée au cours de l'hépatite chronique $\mathrm{C}$ dans une population tunisienne: à propos de 141 cas. La Tunisie Médicale, 91, 327-331.

[14] Arase, Y., Suzuki, F., Suzuki, Y., Akuta, N., Kawamura, Y., Kobayashi, M., Hosaka, T., Sezaki, H., Yatsuji, H., Kobayashi, M., Ikeda, K. and Kumada, H. (2007) Side Effects of Combination Therapy of Peginterferon and Ribavirin for Chronic Hepatitis-C. Internal Medicine, 46, 1827-1832. http://dx.doi.org/10.2169/internalmedicine.46.0289

[15] Lemoine, M., Nayagam, S. and Thursz, M. (2013) Viral Hepatitis in Resource-Limited Countries and Access to Antiviral Therapies: Current and Future Challenges. Future Virology, 8, 371-380. http://dx.doi.org/10.2217/fvl.13.11

[16] Klotz, F. (2003) Quelle prise en charge proposer en Afrique subsaharienne pour les sujets porteurs du virus de l’immunodéficience humaine présentant une hépatite chronique à virus B ou C? Bulletin de la Société de Pathologie Exotique, 96, 237.

[17] Marcellin P. (2010) Prise en charge de l’hépatite chronique B. Recommandations des pratiques cliniques EASL (European Association for the Study of the Liver). Virologie, 14, S74-S80.

[18] Sous la direction du Pr Daniel Dhumeaux et sous l'égide de l'ANRS et de l'AFEF (2014) Prise en charge des personnes infectées par les virus de l'hépatite B ou de l'hépatite C. Rapport de recommandations.

[19] Bourliere, M. (2008) Traitement de l’hépatite C: Gestion des effets secondaires. Gastroentérologie Clinique et Biologique, 32, 166-171. http://dx.doi.org/10.1016/j.gcb.2008.04.019

[20] Larrey, D., Couzigou, P. and Denis, J. (2007) Hépatite chronique C: Gestion des effets indésirables du traitement. Gastroentérologie Clinique et Biologiquel, 31, 20-28. http://dx.doi.org/10.1016/S0399-8320(07)92559-2

[21] Seydia, M., Morlata, P., Bonneta, F., Rambeloarisoaa, J., Bernarda, N., Lacostea, D., Bonareka, M., Trimouletb, P., Ramanampamonjya, R., Lafonb, M.-E., Draméc, M. and Beylota, J. (2005) Efficacité et tolérance de l'association interféron pégylé-ribavirine chez les patients coinfectés VIH-VHC en pratique clinique : étude observationnelle de 32 patients. La Revue de Médecine Interne, 26, 280-287. http://dx.doi.org/10.1016/j.revmed.2004.11.022

[22] Ford, N., Kirby, C., Singh, K., Mills, E.J., Cooke, G., Kamarulzaman, A. and Ducros P. (2012) Chronic Hepatitis C Treatment Outcomes in Low- and Middle-Income Countries: A Systematic Review and Meta-Analysis. Bulletin of the World Health Organization, 90, 540-550. http://dx.doi.org/10.2471/BLT.11.097147

[23] Tyagi, P. and Madan, K. (2008) Have Hematopoietic Growth Factors Made an Impact on the Management of Liver Disease? Trop Gastroenterol, 29, 187-193.

[24] Gournay, J. and Richou, C. (2002) Traitement de l'hépatite chronique C: Effets secondaires, tolérance et qualité de vie. Gastroentérologie Clinique et Biologique, 26, 60-75.

[25] Thevenot, T., Di Martino, V., Mathurin, P., Cervoni, J.-P., Richou, C. and Lunel-Fabiani, F. (2007) Intérêt des facteurs de croissance hématopoïétique au cours du traitement de l’hépatite virale chronique C. Hépato-Gastro, 14, 329-345.

[26] Ayoub, W.S. and Keeffe, E.B. (2011) Review Article: Current Antiviral Therapy of Chronic Hepatitis B. Alimentary Pharmacology \& Therapeutics, 34, 1145-1158. http://dx.doi.org/10.1111/j.1365-2036.2011.04869.x 
[27] Brunetto, M.R., Moriconi, F., Bonino, F., Lau, G.K.K., Farci, P., Yurdaydin, C., Piratvisuth, T., Luo, K., Wang, Y., Hadziyannis, S., Wolf, E., McCloud, P., Batrla, R. and Marcellin, P. (2009) Hepatitis B Virus Surface Antigen Levels: A Guide to Sustained Response to Peginterferon alfa-2a in Hbe Ag-Negative Chronic Hepatitis B. Hepatology, 49, 1141-1150. http://dx.doi.org/10.1002/hep.22760

[28] Hepburn, M.J., Hepburn, L.M., Cantu, N.S., Lapeer, M.G. and Lawitz, E.J. (2004) Differences in Treatment Outcome for Hepatitis C among Ethnic Groups. The American Journal of Medicine, 117, 163-168. http://dx.doi.org/10.1016/j.amjmed.2004.02.043

[29] Conjeevaram, H.S., Fried, M.W., Jeffers, L.J., Terrault, N.A., Wiley-Lucas, T.E., Afdhal, N., Brown, R.S., Belle, S.H., Hoofnagle, J.H., Kleiner, D.E. and Howell, C.D. (2006) Peginterferon and Ribavirin Treatment in African American and Caucasian American Patients with Hepatitis C Genotype 1. Gastroenterology, 131, 470-477. http://dx.doi.org/10.1053/j.gastro.2006.06.008 